\title{
An early warning system for flash floods in hyper-arid Egypt
}

\author{
J. Cools ${ }^{1,2, *}$, P. Vanderkimpen ${ }^{1}$, G. El Afandi ${ }^{3,4}$, A. Abdelkhalek ${ }^{5,6}$, S. Fockedey $^{7}$, M. El Sammany ${ }^{6, * *}$, G. Abdallah ${ }^{6}$, \\ M. El Bihery ${ }^{6, * *}$, W. Bauwens ${ }^{5}$, and M. Huygens ${ }^{1, * * * *}$ \\ ${ }^{1}$ Antea Group, Ghent, Belgium \\ ${ }^{2}$ University of Geneva, enviroSPACE Laboratory, Switzerland \\ ${ }^{3} \mathrm{Al}$ Azhar University, Department of Astronomy and Meteorology, Cairo, Egypt \\ ${ }^{4}$ Tuskegee University, College of Agricultural, Environment and Nutrition Sciences, College of Engineering, Tuskegee, \\ Alabama, USA \\ ${ }^{5}$ Vrije Universiteit Brussel, Department of Hydrology, Brussels, Belgium \\ ${ }^{6}$ Water Resources Research Institute, El Khanater, Egypt \\ ${ }^{7}$ University College West Flanders, Research Group EnBiChem, Kortrijk, Belgium \\ * now at: Cool2Adapt Consult, Ghent, Belgium \\ ** now at: Nile Research Institute, El Khanater, Egypt \\ *** now at: Ministry of Regional Municipalities \& Water Resources, Muscat, Oman \\ **** now at: Dredging, Environmental \& Marine Engineering (DEME), Zwijndrecht, Belgium
}

Correspondence to: J. Cools (jan.cools@gmail.com)

Received: 28 December 2010 - Revised: 5 December 2011 - Accepted: 20 December 2011 - Published: 27 February 2012

\begin{abstract}
An early warning system (EWS) for flash floods has been developed for part of the Sinai peninsula of Egypt, an hyper-arid area confronted with limited availability of field data, limited understanding of the response of the wadi to rainfall, and a lack of correspondence between rainfall data and observed flash flood events. This paper shows that an EWS is not a "mission impossible" when confronted with large technical and scientific uncertainties and limited data availability. Firstly, the EWS has been developed and tested based on the best available information, this being quantitative data (field measurements, simulations and remote sensing images) complemented with qualitative "expert opinion" and local stakeholders' knowledge. Secondly, a set of essential parameters has been identified to be estimated or measured under data-poor conditions. These are: (1) an inventory of past significant rainfall and flash flood events, (2) the spatial and temporal distribution of the rainfall events and (3) transmission and infiltration losses and (4) thresholds for issuing warnings. Over a period of $30 \mathrm{yr}$ (1979-2010), only 20 significant rain events have been measured. Nine of these resulted in a flash flood. Five flash floods were caused by regional storms and four by local convective storms. The results for the 2010 flash flood show that $90 \%$ of the total rainfall volume was lost to infiltration and transmission losses. Finally, it is discussed that the effectiveness of an EWS is only partially determined by technological performance. A strong institutional capacity is equally important, especially
\end{abstract}

skilled staff to operate and maintain the system and clear communication pathways and emergency procedures in case of an upcoming disaster.

\section{Introduction}

Flash floods in arid mountainous regions are destructive natural disasters. A flash flood can be generated instantly during or shortly after a rainfall event, especially when highintensity rain falls on steep hill slopes with exposed rocks and lack of vegetation (Lin, 1999; Wheather, 2002). Flash floods are usually characterized by raging torrents resulting in floodwaves that sweep everything before them. As a consequence, the debris load is mostly high, which further magnifies the destructive power of a flash flood.

The most important processes in arid catchments are: infiltration, routing and transmission losses as described e.g. by Pilgrim et al. (1988), Gheith and Sultan (2002), Foody et al. (2004), Morin (2006) and Bahat et al. (2009). Runoff generation is dominated by infiltration excess rather than saturation excess. Many arid catchments have impermeable hill slopes and highly permeable alluvial channel beds through which floodwater infiltrates. It is not uncommon that no flood is observed at a gauging station, when further upstream a flood has been generated and lost to bed infiltration. The process of transmission losses and channel routing over a dry 
river bed also needs to be explicitly represented in arid watershed modelling tools. For arid areas, evidence exists that simple models perform equally or better than complex models e.g. by Michaud and Sorooshian (1994) in the semi-arid US and Al-Qurashi et al. (2008) in arid Oman. This evidence is in contradiction with the common understanding in temperate or humid areas that complex high-resolution models can represent localized rainfall-events and small-scale processes better.

One effective way to reduce the risk of flash floods lies in the implementation of an early warning system, abbreviated as EWS. When warnings are issued before a flash flood event, additional time is created to take action and save lives and property. The unexpected arrival of a flash flood in combination with its force, limited understanding of the risks, and small space-time scales provide explicit challenges for the development and implementation of an early warning system for flash floods, even in the most advanced regions of the world. For data-poor areas, the challenges are exacerbated. Firstly, the lack of available data is a prime cause of the limited understanding of the flash flood dynamics, which in turn inhibits the calibration and validation of hydrological and hydraulic models. In addition, many of the hydrological models are built for more humid conditions and do not represent arid conditions well. Conventional densities of rain gauge networks furthermore often do not represent the intensity and spatial distribution of rainfall over the catchment well. Secondly, due to the destructive force of a flash flood, flow measurements are lacking or uncertain. In addition, the remoteness, harsh climate, and destroyed roads inside wadis make it difficult to measure and collect field data. The latter makes flash flood events particularly difficult to observe and to predict and prompts the development of alternative data collection strategies. An increasingly popular trend to counteract the lack of data is the use of remote sensing and rainfall forecasting. In current research, mostly done in the European Mediterranean region and semi-arid US, preferences are given to the use of ground radars if available. Alternatives are numerical weather prediction (NWP) and satellite precipitation estimates. Examples of research on flash flood early warning systems are Borga et al. (2007, 2008), Collier (2007), Norbiato et al. (2007), Yatheendradas et al. (2008), Morin et al. (2006, 2009) and Anquetin et al. (2010). A comprehensive review of flash floods in the Mediterranean region is reported by Marchi et al. (2010).

An operational EWS is a system that issues forecasts upon which is acted. Warnings can be issued based on pre-defined thresholds of meteorological observations and/or forecasts, runoff, flow, flood depth or flood extent. In the US, the flash flood guidance (FFG) system operates as part of the much broader National Weather Service River Forecast System (NWSRFS). It takes a different approach as described above as the FFG system tries to estimate the amount of rainfall required to exceed a threshold, given initial states of soil moisture conditions from a hydrological model, and then

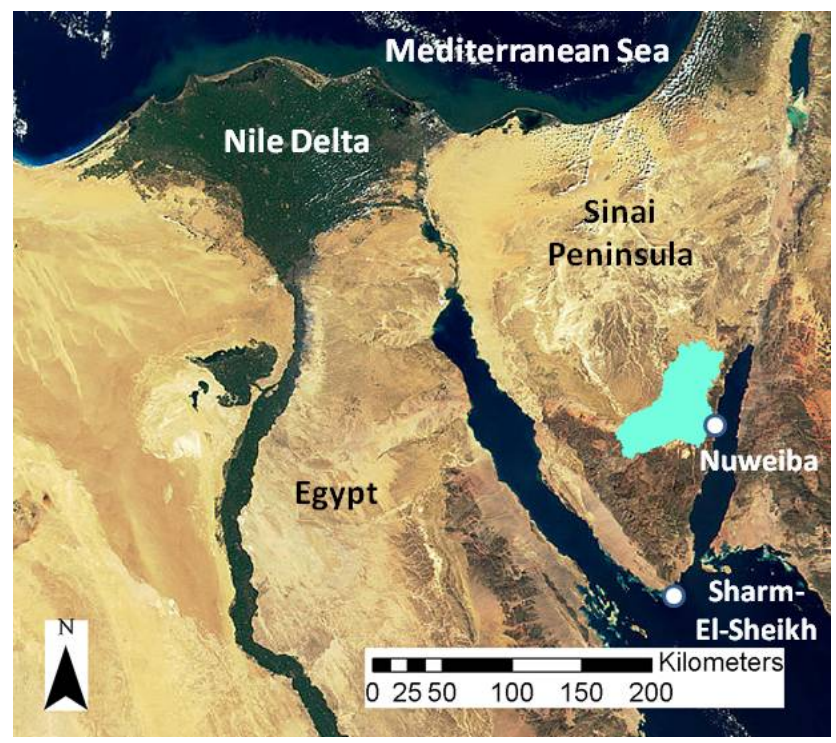

Fig. 1. Location of case study Wadi Watir in the Sinai peninsula of Egypt. Nuweiba is located at the outlet of Wadi Watir. The wellknown tourist city Sharm El-Sheikh is located in the southernmost point of the Sinai peninsula.

evaluates the probability of receiving such rainfall. Other systems are operational but are mostly unpublished, in grey literature or not specifically designed for flash floods. The EWS presented in this paper follows the first method. To the best of the authors' knowledge, it is one of the first operational EWS for flash floods in the hyper-arid areas of the Arab world and Nile Basin countries.

This paper presents the development of an operational EWS for Wadi Watir on the Sinai Peninsula in Egypt. The EWS is developed under the European funded LIFE project "Flash Floods Manager", abbreviated as FlaFloM (www. flaflom.org). The EWS is in an operational testing mode at the Water Resources Research Institute (WRRI) in Cairo, Egypt under the auspices of the Minister of Water and Irrigation. It has already demonstrated its potential through the forecast of the flash floods of 24 October 2008 and 1718 January 2010. Yet, the skills of the system and the (in)tolerance to false alarms need to be further explored. This paper will describe how some of the typical problems encountered in arid areas modelling are tackled, and discuss the challenges related to the development and use of the EWS.

\section{Study area}

Wadi Watir is situated in the South Sinai governorate of Egypt (Fig. 1). It is one of the most active wadis in Sinai with respect to flash floods. The catchment has an area of $3580 \mathrm{~km}^{2}$ and classifies as a hyperarid catchment (Lin, 1999). Average annual rainfall is $35 \mathrm{~mm} \mathrm{yr}^{-1}$, ranging from $10 \mathrm{~mm} \mathrm{yr}^{-1}$ in the low coastal areas to $50 \mathrm{~mm} \mathrm{yr}^{-1}$ in the highland areas. Maximal daily rainfall in South Sinai since 


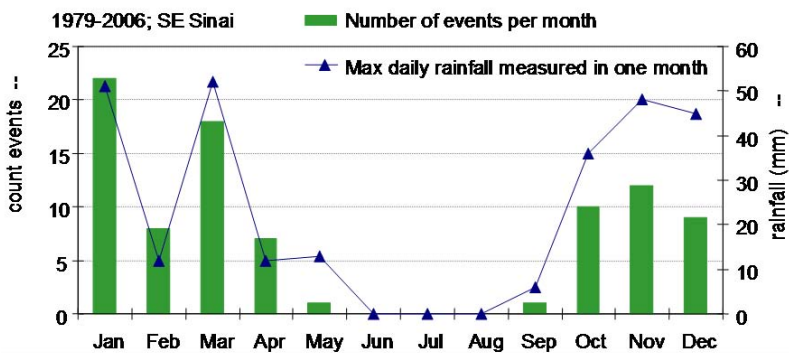

Fig. 2. Distribution of rainfall and storm events from 1979-2006.

1979 is $50.8 \mathrm{~mm}$ measured at Saint-Catherine (mountainous). Potential evapotranspiration is about $1750 \mathrm{~mm} \mathrm{yr}^{-1}$ (Tolba and Gaafer, 2003). The number of rainfall events and the maximum accumulated rainfall during one single day in Wadi Watir is shown in Fig. 2 for the period 1979-2006. Rain is observed from September to May.

The head catchments (about 1400 m elevation) and slopes consist of exposed impermeable rock, whereas the wadi bed is highly transmissive as it is composed of coarse sand and gravel. Mount Saint Catherine $(2629 \mathrm{~m})$, the tallest peak in Sinai, is just south of the catchment limits. Over a distance of $60 \mathrm{~km}$, the Wadi drops from the plateau to sea level via a steep canyon. The upstream part of the canyon is mainly composed of fractured granite and has a terrace structure with alternating flat and steep slopes ranging from 2 to $6 \%$. At the outlet of Wadi Watir in the Gulf of Aqaba (Red Sea), a delta of $40 \mathrm{~km}^{2}$ has formed. In this delta lies Nuweiba city, important for tourism and as a trade port to other Arabic countries.

The common understanding of the origin of most rain events in Sinai is that they are local, convective events with a high spatial variability and short duration, especially around the Red Sea mountain tops. Yet, this is not supported by the synoptic analysis of climatology during major flood events in the Sinai neighbouring areas by Kahana et al. (2002). The authors conclude that the storms in the study area - including the most severe ones - are mainly caused by regional weather systems. They state that only a small amount of storms are local events. This paper aims to contribute reviews of the frequency and scale of rain events on Wadi Watir. Most probably, both local and regional weather phenomena contribute to the occurrence of flash floods in Wadi Watir. This is discussed further in Sect. 4.2.

During flash floods, a high-velocity flood wave with a high sediment load is channelled along the canyon. The flood wave can reach a height of $1-2 \mathrm{~m}$. This usually results in severe damage to the international road, which in some parts is totally washed away (Fig. 4). To protect Nuweiba City, on its vulnerable position at the mouth of the canyon, large investments are made. On the delta, flood diversion dikes have been constructed while upstream five dams, one artificial lake and 2 underground reservoirs have been constructed.

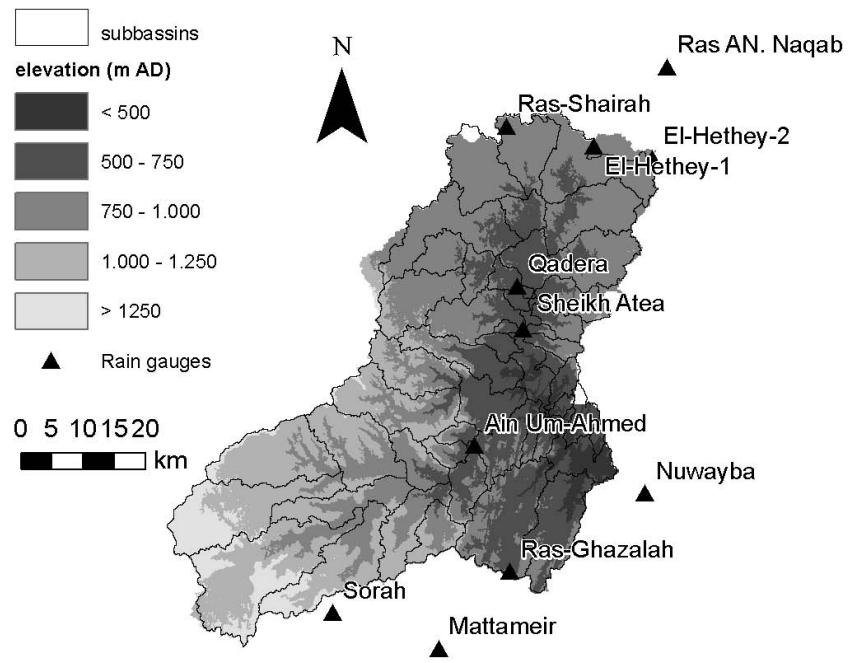

Saint Catherine

$\Delta^{\text {Dahab }}$

Fig. 3. Wadi Watir: topography, subbasins and rain gauges.

The dams are intended to dissipate the power of flash floods and not to block the floodwater entirely. The artificial lake is an open retention basin, which in normal conditions is completely dry. The underground reservoirs are covered, concrete constructions intended to capture floodwater and store it for later use.

The Water Resources Research Institute (WRRI) is the Egyptian governmental research institute with the mandate for flash flood management. WRRI has done rainfall measurements since 1979, collected through manual rain gauges. Up to 2008, only 10 manual gauges were located in the whole Sinai desert (about $60000 \mathrm{~km}^{2}$ ). Only one gauge is located inside Wadi Watir. This is the Sheik Atteia station, located on the plateau in a Bedouin village at the upstream entrance of the canyon. Three other gauges are relevant for Wadi Watir: Nuweiba (Wadi Watir outlet of the canyon), Ras An. Naqb (or alternative name El Tiemeid in the North of Watir on the plateau), and Saint-Catherine (south of Watir, mountainous). In 2007 and 2008, during the FlaFloM project 9 digital rain gauges were installed inside and around Wadi Watir. The locations are shown in Fig. 3. The southern gauges are about $20 \mathrm{~km}$ apart and the northern gauges about $10 \mathrm{~km}$. Hence, the average density of the extended gauge network has increased to about $300-400 \mathrm{~km}^{2}$. Ground radar is not available in the region. Since the installation of the new digital rain gauges in and around the Wadi Watir catchment, two storms have occurred: a local storm event on 23 October 2008 and a regional storm on 17-18 January 2010. The EWS also captured minor rain events which did not result in a flash flood on 15-17 February 2010 and 24-25 February 2010. Results are described in Sect. 4.2. 

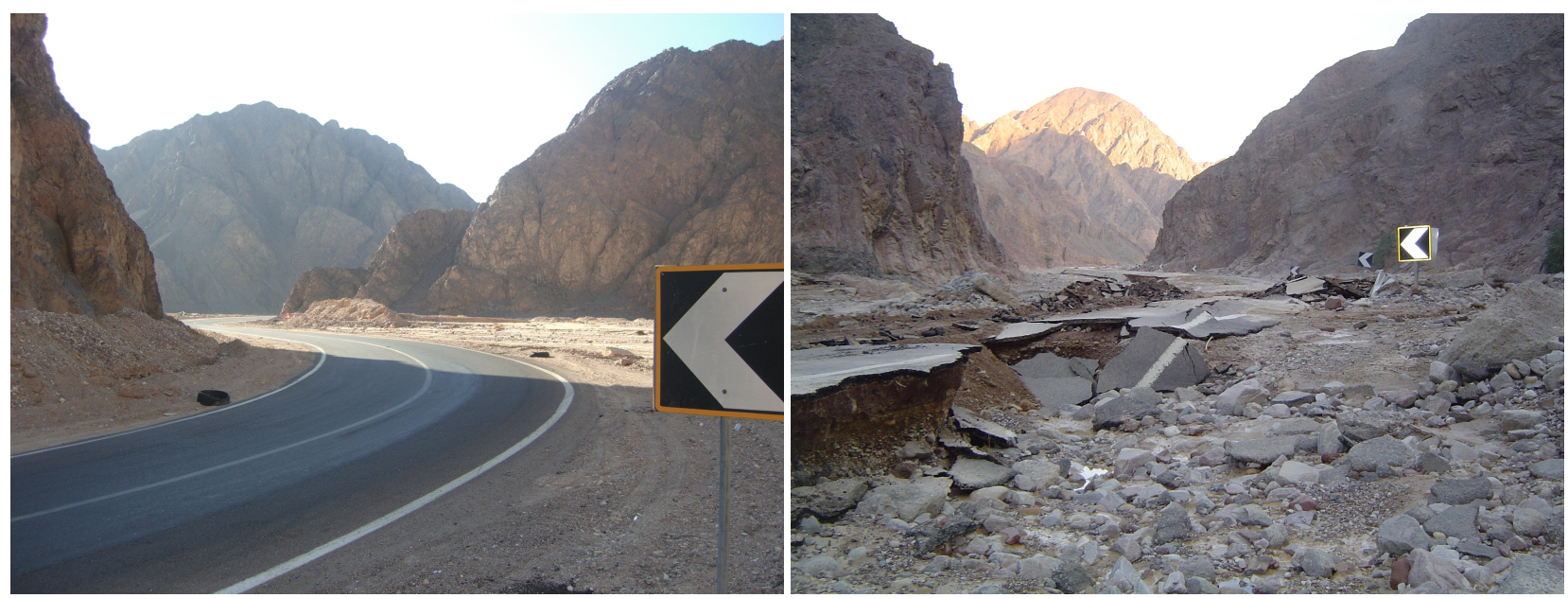

Fig. 4. International road running through the canyon, close to the outlet Wadi Watir. Left: normal state in dry conditions; Right: damage resulting from the flash flood of 24 October 2008.

\section{Early warning system: a chain of components}

The EWS consists of a number of components, linked and activated through an automatic platform. Figure 5 shows the different components. Rainfall forecasting is the first and most essential component. The rainfall data are consequently transformed and aggregated into spatially averaged catchment rainfall for each sub-catchment in the study area. The sub-catchment rainfall forecast serves as input for the rainfall-runoff model. Runoff volumes and discharges are routed through the main channel until the outlet at Nuweiba. The routing can be performed by either using the rainfallrunoff model or a more detailed hydraulic model.

Finally, the EWS sends alerts according to user-defined thresholds of danger. The alert can range from a simple message to a map showing the zones at risk and even a full (automatically prepared) report. A warning will first be handled by an operator to exclude false warnings through rapid desktop screening of simulation anomalies and communication with experts on-the-field (e.g. based on cloud patterns and Bedouin traditional weather knowledge). If positive, the warning is submitted as an external warning to decisionmakers. This gives decision-makers lead time to respond and take actions to avoid (or minimize) damages.

All components are developed, but they are still in an operational testing phase. Forecasted rainfall is currently used for issuing warnings. Due to the limited potential for calibration of the hydrological models, the forecasts on runoff, discharge, and flood depth are done only on a qualitative basis. The effectiveness of communication and decisionmaking procedures for actions is currently under evaluation.

\subsection{Rainfall forecasting}

\subsubsection{Numerical weather prediction for operational rainfall forecasting}

The EWS uses numerical weather prediction as a tool for rainfall forecasting. The forecasts are generated by the Weather Research and Forecasting model (WRF, Skamarock et al., 2008). WRF is a limited area model (LAM) that takes initial and lateral boundary conditions from the Global Forecast System (GFS). WRF also takes the complex terrain (orographic features) of the Sinai Peninsula into account, based on a $3 \mathrm{~km}$ resolution DEM. The GFS is a global NWP run by the US National Center for Environmental Prediction (NCEP), which is a unit of National Oceanic and Atmospheric Administration (NOAA), National Weather Service (NWS). The GFS is run four times per day (00:00, 06:00, 12:00 and 18:00 UTC) and produces forecasts up to $384 \mathrm{~h}$ ahead (16 days) in GRIB format. The spatial resolution of the forecast depends on the forecasting horizon. Up to 3.5 days $(84 \mathrm{~h})$, rainfall is forecasted with a resolution of about $55 \mathrm{~km}$, from 3.5 to 7.5 days $(180 \mathrm{~h})$ with a resolution of about $80 \mathrm{~km}$, and up to day $16(384 \mathrm{~h})$ with a resolution of about $110 \mathrm{~km}$. More information on the application of WRF for the Sinai peninsula is given by Afandi (2010).

Based on the GFS forecasts, WRF produces a series of spatially distributed rainfall grids with an hourly time step at two spatial scales: (1) a $30 \mathrm{~km}$ resolution for the whole of Egypt and (2) a $3 \mathrm{~km}$ resolution only for Wadi Watier. The $30 \mathrm{~km}$ rainfall forecast corresponds to $8-9$ pixels over Wadi Watir whereas the $3 \mathrm{~km}$ resolution grid corresponds to 400 pixels. It could not be assessed, as a consequence of the limited data availability, which resolution provides better results. On the one hand, rainfall forecasts with a $3 \mathrm{~km}$ resolution allow for a better spatial distribution of rainfall 
and better capturing of peak intensities incl. orographic effects and convective rainfall (important for the mountainous Wadi Watir). On the other hand, a higher resolution forecast is expected to improve the forecasted rainfall but not the forecasted runoff and flow. The added value of high resolution rainfall forecasts for the forecast of runoff and flow is limited, considering that the rainfall-runoff model requires sub-catchment average rainfall and considering the limited insight in the spatial heterogeneity of infiltration and transmission losses.

The resolution of rainfall forecasts for operational purposes is mainly a question of resources. Given that the operator of the EWS is responsible for flash flood risk management in the whole of Egypt, country-wide forecasts are preferred to a more detailed forecast for a single wadi. Forecasting rainfall at high resolution for nations like Egypt is still too demanding in terms of forecasting time - which takes away precious lead time - and computer resources.

\subsubsection{Satellite precipitation estimates: analysis of historic flash flood events}

Currently, satellite precipitation estimates are not directly useable for an EWS, due to the delay between acquisition and transmission of the images and the fact that satellite precipitation estimates are considered as observations and not forecasts. Satellite precipitation estimates nevertheless played a key role in the development and testing of the EWS. From the in-situ rainfall measurements, a lack of correspondence appeared with the observed flash flood events as elaborated in Sect. 4.2. In addition, insufficient clarity existed on the date, spatial extent, and approximate duration of the different events. For this purpose, the visualisation tool TRMM Online Visualization and Analysis System (TOVAS) was used to search through the archives of the Tropical Rainfall Measuring Mission (TRMM Daily records 3V42) and the Global Precipitation Climatology Center (GPCC) for the period 1987-2010. In terms of quality, the 3V42 product is currently the best TRMM product for model validation purposes. In order to develop this product, all of the available passive microwave data are converted to precipitation estimates prior to use, then each data set is averaged to the $0.25^{\circ}$ spatial grid over the time range $\pm 90 \mathrm{~min}$ from the nominal observation time. All of these estimates are adjusted to a "best" estimate using probability matching of precipitation rate histograms assembled from coincident data. For detailed information on these products the reader is referred to Huffman and Bolvin (2008).

Table 1 shows the result of this analysis. Especially older events (before 2000) showed a poor match between different types of data for different events and periods. From then on, the events were better documented and the estimation algorithms have been improved. Therefore, only the recent flash flood events have been used in the development of the EWS. To conclude, satellite precipitation estimates have only been

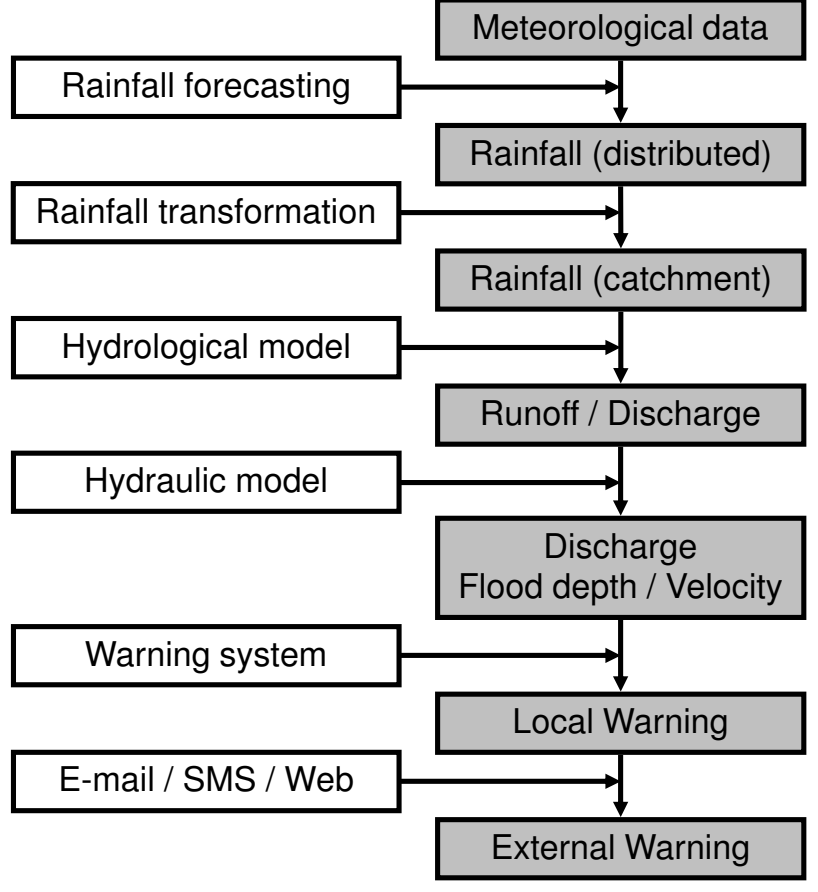

Fig. 5. The chain of components that forms the early warning system.

used for the identification and analysis of historic flash flood events and are not being used for rainfall forecasting in the EWS.

\subsection{Hydrological and hydraulic model}

To model the specific arid zone hydrological characteristics, a discrete event lumped rainfall-runoff model was developed. A schematic view of the modelled processes is presented in Fig. 6. Based on the rainfall forecast, the rainfall-runoff model calculates the excess rainfall. Pervious and impervious areas are modelled separately (see Sect. 4.3 assessing infiltration and transmission). Initial losses (interception and wetting) are modelled by means of a conceptual reservoir, which is constantly depleted by evaporation. The calculation of depression storage is based on an empirical technique developed by Harms and Verworn (1984). Infiltration losses in pervious areas are estimated by means of the Green and Ampt method (Green and Ampt, 1911). In impervious areas, some water might still infiltrate through cracks. These losses are accounted for by means of an empirical runoff coefficient. Overland flow within a sub-catchment is then computed by means of a Nash cascade (Chow et al., 1988). A detailed description of the rainfall-runoff model is available in Abdelkhalek (2011).

The runoff from each subcatchment is routed through the network of wadis by means of the Muskingum method (Chow et al., 1988). Transmission losses in the highly 
Table 1. Historic flash flood events in Wadi Watir and correspondence to rainfall events: ${ }^{1} 3$ operational rain gauges in Wadi Watir until 2007, afterwards 9 more gauges were installed; ${ }^{2}$ Range of satellite rainfall estimates by TRMM (product 3B42(V6)).

\begin{tabular}{|c|c|c|c|c|c|c|}
\hline ID & Dates & $\begin{array}{c}\text { In-situ rainfall } \\
\text { observations } \\
\text { (no. of stations) }\end{array}$ & $\begin{array}{l}\text { Type of } \\
\text { storm } \\
\text { event }\end{array}$ & $\begin{array}{l}\text { Flash } \\
\text { flood }\end{array}$ & $\begin{array}{l}\text { In-situ } \\
\text { acc. rainfall } \\
(\mathrm{mm})\end{array}$ & $\begin{array}{l}\text { Acc. rainfall } \\
\text { above Wadi Watir } \\
(\text { remote })^{2}\end{array}$ \\
\hline 1 & 16 Oct 1987 & 0 & Regional & Disaster & - & $15-20 \mathrm{~mm}$ \\
\hline 2 & 20 Dec 1987 & 1 & Local & - & $10 \mathrm{~mm}$ & - \\
\hline 3 & 1 Apr 1988 & 0 & Local & Weak & - & $0-1 \mathrm{~mm}$ \\
\hline 4 & 17 Oct 1988 & 0 & Local & Moderate & - & $1-3 \mathrm{~mm}$ \\
\hline 5 & 12 Mar 1990 & 2 & - & - & $5 \& 51.5 \mathrm{~mm}$ & - \\
\hline 6 & 23 Oct 1990 & 1 & Regional & Moderate & $5 \mathrm{~mm}$ & $1-2 \mathrm{~mm}$ \\
\hline 7 & 22 Mar 1991 & 3 & Regional & - & $11-36.5 \mathrm{~mm}$ & - \\
\hline 8 & 1-2 Jan 1994 & 3 & Regional & - & $10-21 \mathrm{~mm}$ & - \\
\hline 9 & 2 Nov 1994 & 3 & Regional & - & $1-16.5 \mathrm{~mm}$ & - \\
\hline 10 & 17-18 Nov 1996 & 3 & - & - & $3-19 \mathrm{~mm}$ & - \\
\hline 11 & 14 Jan 1997 & 2 & - & - & $7 \& 8 \mathrm{~mm}$ & - \\
\hline 12 & 17-18 Oct 1997 & 0 & Regional & High & - & $10-20 \mathrm{~mm}$ \\
\hline 13 & 15 Jan 2000 & 1 & Local & - & $11 \mathrm{~mm}$ & - \\
\hline 14 & 9 Dec 2000 & 2 & Regional & - & $5 \& 5 \mathrm{~mm}$ & $7 \mathrm{~mm}$ \\
\hline 15 & 27-31 Oct, 3 Nov 2002 & 2 & Regional & Moderate & $9 \& 16 \mathrm{~mm}$ & $4-10 \mathrm{~mm}$ \\
\hline 16 & 15 Dec 2003 & 1 & Local & - & $5 \mathrm{~mm}$ & $0-1 \mathrm{~mm}$ \\
\hline 17 & 5 Feb 2004 & 1 & Local & - & $8 \mathrm{~mm}$ & - \\
\hline 18 & 29 Oct 2004 & 0 & Local & Weak & - & $12 \mathrm{~mm}$ \\
\hline 19 & 24 Oct 2008 & 2 & Local & Moderate & $0.8 \& 11 \mathrm{~mm}$ & - \\
\hline 20 & 17-18 Jan 2010 & 8 & Regional & High & $11-30 \mathrm{~mm}$ & $30 \mathrm{~mm}$ \\
\hline
\end{tabular}

permeable wadi bed are accounted for by means of an empirical loss coefficient. For the purposes of visualisation, the Muskingum routing was implemented in a commercial hydraulic modelling software package ("InfoWorks-RS", distributed by Innovyze, 2008).

The Wadi Watir catchment is subdivided into 48 subcatchments. This high number of subcatchments was chosen to enable the simulation the rapid (flashy) responses that characterize flash floods.

The lack of discharge data in Wadi Watir prohibits a datadriven calibration of the rainfall-runoff model and the hydraulic model. To date, the model parameterization is done based on literature data and expert judgment. In order to assess the accuracy of the model qualitatively, the outputs have been compared to flood volumes and flood depths estimated in WRRI (2004) and to the insights of local experts and inhabitants. Once discharge data become available, the modelling parameters need to be further adjusted. For this reason, the rainfall-runoff model as well as the hydraulic model are currently in the testing phase and not (yet) part of the currently operational EWS.

As the rainfall-runoff model is a component of an EWS, two main improvements have been done compared to off-line rainfall-runoff models: (1) automated routines have been developed such that received rainfall forecasts are transformed automatically from a raster format into a sub-catchment averaged rainfall, read into the model, and produce outputs in a format used by the hydraulic model; (2) the output files have real time stamps, an essential functionality for an EWS.

The hydraulic model is used to deliver flood maps for the downstream reaches of the main canyon. It predicts the flows in the main wadis and the water levels in the storage reservoirs. Included in the model extent are the two main Bedouin villages (Sheikh El Atteia and Ain Um Ahmed), the existing dams and reservoirs, and the delta of the Wadi Watir with the diversion dikes as characteristic infrastructure (as shown e.g. in Fig. 1). The hydraulic model is driven by the (real-time) runoff hydrographs obtained from hydrological simulations for the entire catchment.

The inclusion in an operational real-time system requires that the hydraulic model is robust: it needs to be numerically stable and perform fast simulations. Given that the canyon of Wadi Watir is characterized by steep slopes and occasionally supercritical flows (but not backwater effects), a full, hydrodynamic model would be continuously prone to numerical instabilities. For these reasons, classical hydrodynamic routing was replaced by a simplified hydrologic Muskingum routing, with the addition of a transmission loss coefficient. Such a routing model is fast and numerically stable, but it only produces discharges. By using discharge-stage and discharge-velocity relationships, the model can also produce water levels and flow velocities, but these are only estimates and not exact values. Cross-sections of the canyon are derived from the $5 \times 5 \mathrm{~m} \mathrm{DEM}$. 


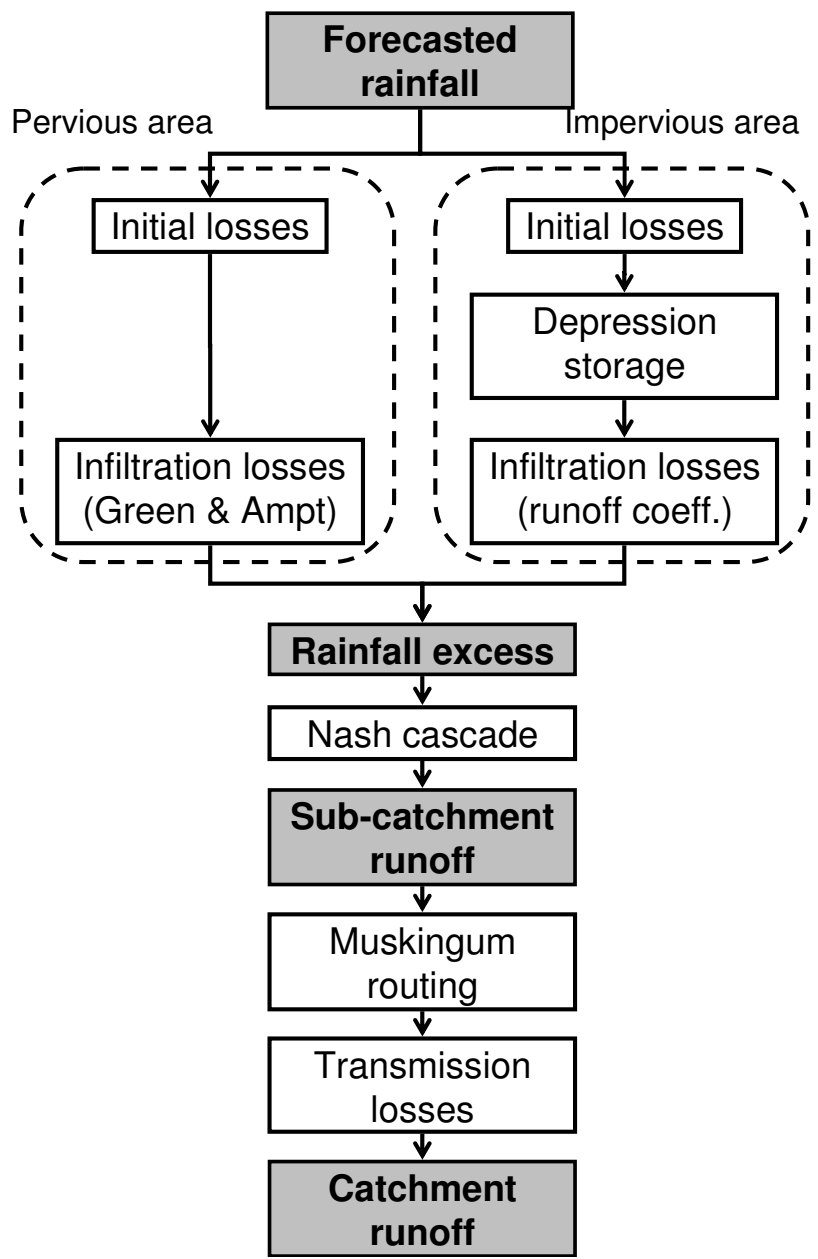

Fig. 6. Schematic view of the hydrological processes considered at the catchment.

\subsection{Infiltration and transmission losses}

In the catchment models presented in this paper, the most important calibration parameters are those related to infiltration and transmission losses. Based on the geological map and expert judgment, the rainfall-runoff model consists of two land types: the hill slopes and head catchments are considered as impermeable rock whereas the alluvial wadi deposits are classified as pervious (sand and gravel). Similar categories are used by Gheith and Sultan (2002) and Foody et al. (2004). The spatial distribution of pervious and impervious areas for each sub-catchment is derived from the stratigraphic geological map. In order to do so, the hydrogeological properties of each stratigraphic formation are assessed and consequently classified as pervious or impervious irrespective of their geological age. A similar methodology is followed as in USDA (1986), Chow (1988) and Cools et al. (2006). Pervious formations are mainly loose Quaternary alluvial wadi deposits and fanglomerates, consisting of coarse sands and gravels. Impervious formations are formed by primary rocks such as cemented sand and limestones, shales, granites, acid volcanics.

Infiltration rates for the wadi deposits are available from laboratory infiltration tests. The values range from $0.66-$ $72 \mathrm{~mm} \mathrm{~min}^{-1}$ for the initial infiltration rate and 0.62 $51.4 \mathrm{~mm} \mathrm{~min}^{-1}$ for the final infiltration rate, which is attained relatively quickly in arid catchments (after 15 min$1 \mathrm{~h}$ ). WRRI (1995), based on soil texture, estimated similarly high values for the initial losses $(5-32 \mathrm{~mm})$ but lower values for the constant losses $\left(0.33-25.4 \mathrm{~mm} \mathrm{~h}^{-1}\right)$.

Considering that the lumped rainfall-runoff model cannot represent the hydrogeological heterogeneity well, a mean value of $2 \mathrm{~mm}$ for the initial losses and $2 \mathrm{~mm} \mathrm{~min}^{-1}$ as the final infiltration rate is chosen at the lower end of the interval. Since the wadi deposits are often interlayered with silty sediment drapes, a reduced effective infiltration rate might fit to reality. At the same time, hydrophobic processes could initially prevent water from infiltrating in the dry soil. As a consequence, coarse sandstone with high measured infiltration rates could act as a rather impervious surface for a passing flood wave.

For the impervious formations, a qualitative expertjudgment based assessment of the presence of cracks has been done as well. Large cracks in impervious rock formations can quickly remove rainfall from the surface, feeding it underground to wells in the area. Cracks are not studied in detail and this information mainly served to estimate the lumped runoff coefficient. For the impervious areas, a runoff coefficient of 0.8 is used in the rainfall-runoff model.

In the hydrological routing model, transmission losses are estimated by means of an empirical loss coefficient. Transmission losses are estimated at $20 \%$ of the total flow in a model branch. They are subtracted at each node, connecting two or more branches.

\subsection{Warning system}

The EWS issues warnings whenever pre-defined thresholds are exceeded. Thresholds can be defined for rainfall, runoff, water level, and discharge and can be issued from each component of the chain that composes the EWS. For each of these, three different thresholds can be defined. The first threshold ("start") indicates the onset of rainfall, runoff, and discharge or the presence of some water in the reservoirs; the second threshold ("warning") indicates the possibility of dangerous floods; the third threshold ("alert") indicates a high likelihood of dangerous floods. In the current operational system, only a rainfall threshold has been applied. Based on local experience with flash floods in the Sinai Peninsula, a warning is issued when the cumulative rainfall over a $6 \mathrm{~h}$ period exceeds $10 \mathrm{~mm}$. When the cumulative rainfall exceeds $15 \mathrm{~mm}$, an alert is issued. Insufficient insights currently exist to set and validate other thresholds.

The EWS operates from a software platform (Floodworks, Innovyze) that automatically activates and ensures the 
communication between the components of the EWS. Warnings are issued on-screen in the user interface and are sent by e-mails to pre-defined addresses. Future extensions will enable sending warnings via text messages (SMS) and publishing forecasts on a website.

Although the steps to come to a flash flood warning are elaborate, the system is designed to deliver forecasts in less than $15 \mathrm{~min}$ and forecasts $24 \mathrm{~h}$ in advance. Considering that the required lead time for an effective response is about $2 \mathrm{~h}$, the lead time requirements are met by the system. Yet, in practice some elements may lead to seriously lower lead times. These include the operational difficulties to forecast $24 \mathrm{~h}$ a day such as the absence of an operator at night or on the weekends, a power failure which inhibits the EWS to run, system crashes, and inter-human communication and decision-making.

\subsection{Communication and decision-making}

Crucial for the operational use of an EWS are the steps taken between the issuing of a warning to the actual actions on the ground. Actions can be taken before, during, and after a flash flood. In this section, an overview is given of the expected communication pathways shortly before and during a flash flood.

Operators at WRRI send a daily report by e-mail to all governors in Egypt, with hourly and accumulated WRF rainfall forecasts. If rainfall is forecasted, the operator adds an accompanying note with his interpretation. Before sending, a warning will first be handled by an operator to exclude false warnings. The latter is done through rapid desktop screening of simulation anomalies (e.g. errors in the input) and communication with experts on-the-field (e.g. based on cloud patterns and Bedouin traditional weather knowledge). For "alert" warnings (such as the January 2010 event), the WRRI operator also warns the Sinai governors by phone. Decisions for actions are taken by the South Sinai governorate officials, who in turn warn the municipal officials in Nuweiba. The latter forward the warning and associated decision to the municipal technical services (police, fire brigade, traffic office, post office) and local inhabitants. The traffic office prepares for blocking the roads running through the wadi and to the harbour.

\section{Results and discussions}

\subsection{Challenges for a flash flood early warning system in a hyperarid catchment}

Many challenges exist for the development and use of an EWS for flash floods in a hyper-arid catchment. Major technical challenges are related to inconsistencies in the available data. Although rainfall time series from a network of rain gauges are available from 1979 onwards, the time series firstly had an insufficient level of detail and some lack continuity. The exact date and temporal distribution e.g. was often missing or inconsistent. Insufficient insight furthermore existed on the spatial variability and intensity of rainfall events. In addition, a lack of correspondence is observed between rainfall data and observed flash flood events. As described in Sect. 3.1.2., satellite precipitation estimates have been used to provide more clarity on the temporal and spatial characteristics of rainfall events and the associated correspondence with flash floods. Secondly, only estimates of discharge and water level are available. As a consequence of the destructive force of flash floods, an existing weir has been destroyed and has not resulted in measurements. Only indirect values or qualitative expert judgment based assessments are available. These are firstly flood volume based peak discharges as e.g. estimated in WRRI $(1995,2004)$ and secondly visual observations by local experts, lay people (Bedouins), and videos and photos taken during and after the flash flood.

From a social point of view, major challenges are the necessary participative interaction with the local authorities for flash flood management and the local inhabitants (mostly Bedouins) and the coordination of communication pathways from the generated warning to actual decision-taking on the field. Egyptian officials and the Bedouins furthermore have a mutual distrust. As a consequence, in the past, rain gauges have been destroyed as some Bedouins felt them to be an intrusion on their privacy. The latter adds to the logistic challenges of a flash flood EWS and endangers a long-term acquisition of field measurements, which in turn inhibits a better understanding of the flash flood risk. Hyper-arid catchments are generally difficult to access, especially during and soon after a flash flood. From a communication point of view, it was challenging to establish a clear communication pathway from the moment when the warning was generated to the actual decision-taking by local authorities. Since the EWS requires significant technical capacity to be operated, warnings are sent from a national governmental research institute (WRRI) in Cairo to the local authorities in the catchment. In addition, given the above limitations of the EWS, it is expected that initially the forecasts may show some bias due to the previously mentioned reasons. To secure a positive image of the EWS relative to the decision-makers and stakeholders, the sending out of false warnings and lack of warnings (when a flash flood did occur) needed to be avoided. For this purpose, currently only rainfall forecasting is used to send out official warnings. The other components are still in the operational testing phase until sufficient trust is gained.

\subsection{Correspondence between rainfall data and flash flood events}

An analysis of the observations, both time series of rainfall measurements, and flash flood observations revealed an apparent lack of correspondence between the two. Between 1979 and 2010, 20 significant storm events occurred in Wadi 
Table 2. Qualitative comparison of the available rainfall data from in-situ measurements, WRF forecasts, and satellite estimates for rain events since 2002 .

\begin{tabular}{|c|c|c|c|c|c|c|}
\hline \multirow[b]{3}{*}{ Date } & \multirow[b]{3}{*}{ Flash flood } & \multicolumn{4}{|c|}{ Max. cumulative rainfall $(\mathrm{mm})$} & \multirow{3}{*}{$\begin{array}{r}\text { In-situ } \\
\text { observations (mm) }\end{array}$} \\
\hline & & \multicolumn{3}{|c|}{ WRF rainfall forecast } & \multirow[t]{2}{*}{$\begin{array}{l}\text { TRMM } \\
\text { estimate }\end{array}$} & \\
\hline & & Convective & Non-convective & Total & & \\
\hline 30 Oct 2002 & Moderate & - & - & - & 10 & 9 \\
\hline 15 Dec 2003 & - & 36 & 0 & 36 & - & - \\
\hline 5 Feb 2004 & - & 7.5 & 6 & 13.5 & - & 8 \\
\hline 29 Oct 2004 & Weak & 5 & 0 & 5 & 12 & - \\
\hline 28 Mar 2006 & - & 14 & 0 & 14 & - & _- \\
\hline $23-24$ Oct 2008 & Moderate & 2 & 0 & 2 & - & $0.3-11$ \\
\hline 17-18 Jan 2010 & High & 8.5 & 27.5 & 36 & 30.5 & $11-30$ \\
\hline
\end{tabular}

Watir. An overview is given in Table 1 and results from a comparison between the data logs of flash floods, in-situ rainfall measurements, and a search through the archives of satellite precipitation estimates (as elaborated in Sect. 3.1.2). All flash floods, irrespective of the rainfall volumes, caused severe damage to existing infrastructure, mainly the road and wells for water supply (both traditional wells and commercial deep wells).

Nine storm events resulted in a flash flood in the downstream canyon or at Nuweiba. In five out of nine flash floods (1987, April and October 1988, 1997 and 2004), no in-situ rainfall was measured. For the flash flood of 1990, rain was only observed in one gauge $(5 \mathrm{~mm})$, whereas rainfall was measured in 2 gauges $(9$ and $16 \mathrm{~mm}$ ) for the OctoberNovember 2002 flash flood. For the two most recent flash floods (October 2008 and January 2010), following the installation of 9 new rainfall gauges rainfall was observed in 2 gauges for the 2008 flash flood and in 8 gauges for the 2010 flash flood. For the 2008 event, however, significant rainfall $(10.8 \mathrm{~mm})$ was only measured in 1 gauge, namely the Sorah gauge $(11 \mathrm{~mm})$. The El-Dalal gauge at a distance of $20 \mathrm{~km}$ measured a small volume of $0.8 \mathrm{~mm}$; All other gauges remained dry. For the 2010 flash flood, rainfall is measured in 8 stations with a coverage of the whole Wadi Watir. In-situ rainfall volumes were measured between 11 and $30 \mathrm{~mm}$. Although rainfall volumes of $10-30 \mathrm{~mm}$ are relatively small, others found similar values. Also in Wadi Watir, an extreme value analysis by Abdelkhalek (2011) resulted in rainfall amounts of $10-15 \mathrm{~mm}$ for a 5 -yr return period to 20 $30 \mathrm{~mm}$ for a $25 \mathrm{yr}$ return period. Bahat et al. (2009) reports 16 selected rainfall-runoff events of the Elat station (about $100 \mathrm{~km}$ north of Wadi Watir). In eight of the events, minor rainfall of 3-8 $\mathrm{mm}$ generated runoff. For five events it rained between $18-32 \mathrm{~mm}$.

The relationship between rainfall volumes and the occurrence of a flash flood is not straightforward. Behind the most severe flash floods (1987, 1997 and 2010) are indeed wide-spread regional storm events which resulted in - for arid areas - large rainfall volumes over the whole catchment of $10-20 \mathrm{~mm}$ with a maximum to $30 \mathrm{~mm}$ for the 2010 flash flood. For these events, large rainfall volumes resulted in a severe flash flood. Yet, as shown in Table 1, not all major rain events generated a flash flood. For five storm events (March 1990, March 1991, January and November 1994 and November 1996), a flash flood was not observed despite rainfall observed in 2 or 3 rain gauges. At least $5 \mathrm{~mm}$ of rainfall fell over a large area with maxima above $15 \mathrm{~mm}$. In March 1990, maximal rainfall was observed up to $51.5 \mathrm{~mm}$ (Sheik Attia) and $36.5 \mathrm{~mm}$ (Saint Catherine) in March 1991. Considering that Sheik-Attia is located in a wide, gravelly plateau, it can be motivated that all rainfall is lost to infiltration and hence no flash flood was generated. Higher rainfall - and especially local convective rainfall - on the mountainous Saint-Catherine gauge can also be expected, but is not necessarily resulting in an increased probability for runoff, considering that Saint Catherine is located outside of Wadi Watir. Finally, three historic flash floods (March and October 1988 and 1990) were caused by a satellite rainfall estimate below $3 \mathrm{~mm}$. Although the latter can not be validated due to the lack of in-situ measurements, the estimate is considered to be underestimated.

In order to obtain an insight in the scale, spatial and temporal distribution of the storm events, the in-situ data are complemented with rainfall maps from two sources: rainfall satellite estimates and WRF forecasts and hindcasts. Rainfall estimates are accessed from the TRMM 3-hourly archive. Rainfall hindcasts with WRF are made for the events since 2002. A qualitative comparison of the available rainfall data from in-situ measurement, WRF forecasts and satellite estimates is shown in Table 2. For the WRF forecast, a breakdown is given for convective and non-convective rainfall. A selection of TRMM images is shown in Fig. 7 both for local, convective, storm events (examples are the 2002 and 2004 event) and the wide-spread, regional (mostly) non-convective events such as the 2000 and 2010 event. The WRF rainfall forecast $(30 \times 30 \mathrm{~km}$ resolution) of the 2010 flash flood is 
shown in Fig. 8. As shown in Table 2, WRF has forecasted all 7 events since 2002, except the 2002 event. All events, except the January 2010 event, were local events where only (or mostly) convective rain was estimated. TRMM captured only the regional scale ( 3 out 7 ) but included 3 out of 4 flash floods. TRMM only missed the 2008 flash flood. In-situ measurements are available for 4 out 7 events, including the flash floods of October 2008 and January 2010.

A comparison of cumulative rainfall between the field gauge measurements and WRF forecast is shown in Figs. 910 for the 2010 flash flood and in Fig. 11 for the 2008 flash flood (where only one gauge measured significant rainfall). The WRF values are selected at the pixels corresponding to the locations of the rain gauges. Figure 9 (total rainfall volume) and Fig. 10 (time series of 3 rain gauges out of 8) shows an overestimation of about $5-15 \mathrm{~mm}$, with bias decreasing with increasing rainfall. According to Fig. 10, WRF has predicted the rainfall ranging from a $3-5 \mathrm{~h}$ time lag (anticipation) to $3 \mathrm{~h}$ after the start of the rain event depending on the location within the Wadi. For the local storm event of October 2008, where only rain is measured in one rain gauge (Sorah, mountainous south-west of Wadi Watir), a similar time lag of $5 \mathrm{~h}$ in anticipation is observed, but the total rainfall is underestimated by $2 \mathrm{~mm}$. The underestimation for the convective 2008 storm event can be motivated by the fact that the orographic effects on rainfall are not well represented in WRF considering its pixels of $30 \times 30 \mathrm{~km}$. In addition, it improves the probability of forecasting a major event. Secondly, during and for days after a flash flood, the access to the gauges might be inhibited. The accumulated sample might have become irrecoverable by debris flow or other reasons.

The inconsistency of in-situ data is commonly explained by the dominance of very local rainfall events (which are missed by the gauges) and the high transmission losses in wadi beds which may cause even significant rainfall to be lost to infiltration and hence not release a flash flood. Although the origin of flash floods is complex and requires more research, the arguments of small scale storms and high transmission losses can only partly explain the inconsistencies as shown in Table 3. Here the storm events are classified as a local, convective, storm event or a wide-spread, regional (mostly) non-convective event based on the following criteria: extent in rainfall maps, significant in-situ rainfall in 2 or more rain gauges, events described in literature in neighbouring areas. Remarkably, the events are equally divided: 9 regional events, 9 local events and 3 older events (before 1997) that are unclear due to lack of spatial data. Half of both the regional and local events led to a flash flood whereas the rainfall volume of the other $50 \%$ of storm events infiltrated and evaporated. Out of the 9 storm events that caused a flash flood, 5 were regional storms (1987, 1990, 1997, 2002 and 2010 events) and 4 local convective storms (April and October 1988, 2004 and 2008 events). It can be concluded that regional storms are as frequent as local storms. Regional storms thus play a bigger role than commonly perceived
Table 3. Overview of type of storms of Wadi Watir in the period 1987-2010.

\begin{tabular}{lccc}
\hline Type of storm & flash flood & no flash flood & Total \\
\hline Regional & 5 & 4 & 9 \\
Local & 4 & 5 & 9 \\
Unclear & 0 & 3 & 3 \\
\hline Total & 9 & 12 & 21 \\
\hline
\end{tabular}

(mostly local events with limited spatial extent) but they are not the dominant weather type as stated by Kahana et al. (2002) for a nearby catchment.

Further explanatory factors are inherently related to the operational monitoring of flash floods. Firstly, more data are available for the more accessible stations from which the data are more regularly collected and which are also better maintained. From the end of the 90's onwards until 2007, there are fewer operational stations and this results in a discontinuity in the time series. The low probability of rainfall linked to a limited understanding of the spatial and temporal distribution of rainfall and peak rainfall intensities, furthermore, does not facilitate the selection of the best location for rain gauges and their long-term operation. In addition to the generally difficult accessibility of arid wadis, during flash floods the access to the gauges might become impossible until days after the event, when the accumulated sample might have evaporated or become irrecoverable by debris flow or other reasons. As well, despite the precautionary measures, gauges and water level infrastructure have in some cases been destroyed by the force of the flash flood. The latter evidently results in discontinuous or uncertain time series.

\subsection{Forecasting runoff and discharge}

The simulation of runoff and discharge for hyper-arid and data-scarce areas like Wadi Watir is highly challenging due to the limited availability of data and limited understanding of the infiltration and transmission losses. Given that no measurements of runoff and discharge existed, the model has been calibrated based on an observed maximum flood depth of $1.5 \mathrm{~m}$ at the outlet of Wadi Watir (near Nuweiba) for the January 2010 flash flood. Despite the limited potential for calibration and the uncertainty on the observed start-end of the flood wave, the forecast of the 2010 flash flood is of an acceptable quality, as shown in Fig. 12, and corresponds to the observed maximum flood depth and duration (30-35 h).

At the outlet of the wadi, a peak discharge of $235 \mathrm{~m}^{3} \mathrm{~s}^{-1}$ and a maximum water depth of $1.52 \mathrm{~m}$ was forecasted. The first discharge at the outlet was forecasted at midnight ( 0 a.m. on 18 January 2010). Although no comparable observations exist, the latter forecast is considered acceptable given that the first rainfall is observed at 9 p.m. on 17 January 10 and 

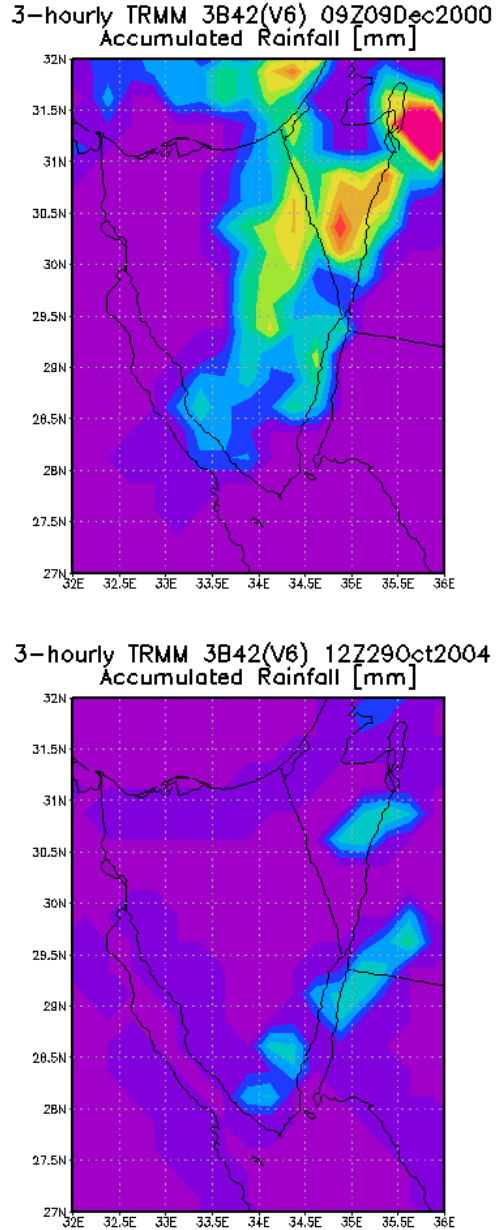

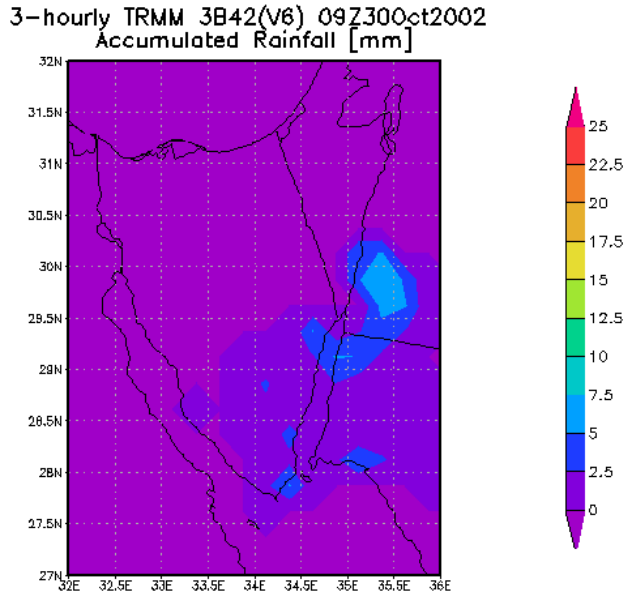

3-hourly TRMM 3842(V6) 15Z17Jan2010-18Z18Jan2010

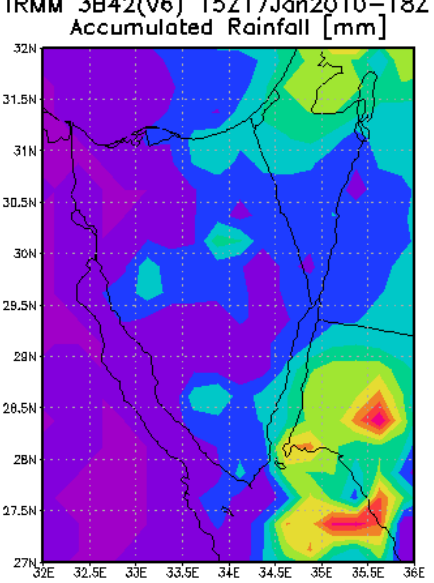

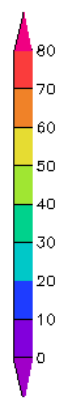

Fig. 7. Selection of 3-hourly rainfall estimates from TRMM for the events in December 2000, October 2002, October 2004, and January 2010. Images have been extracted with NASA's Giovanni (http://giovanni.gsfc.nasa.gov).

considering that local observers claim that the flood wave takes about $2 \mathrm{~h}$ to arrive at the exit. A first discharge peak was reached $2 \mathrm{~h}$ after peak rainrate $\left(2\right.$ a.m.; $\left.17 \mathrm{~mm} \mathrm{~h}^{-1}\right)$, a second peak $7 \mathrm{~h}$ later. Recession thus started $10 \mathrm{~h}$ after the start of rainfall. As a consequence of a second small rain event (about $5 \mathrm{~mm} \mathrm{~min}^{-1}$ depending on the sub-catchment), the discharge remained around $70 \mathrm{~m}^{3} \mathrm{~s}^{-1}$ until 8.30 a.m. on 19 January. Discharge stopped around 4 p.m. After $21 \mathrm{~h}$, the water depth was observed to have dropped below $30 \mathrm{~cm}$. That time is noted as the end of the flash flood.

The specific runoff $(\mathrm{mm})$ simulated by the rainfall-runoff model for each of the individual sub-catchments ranged from $20-28.75 \mathrm{~mm}$ with an average of $25 \mathrm{~mm}$. Given that subcatchment rainfall ranged from 33 to $40 \mathrm{~mm}$, runoff coefficients of $54-81 \%$ with an average of $67 \%$ are obtained. After routing the sub-catchment runoff through the wadi by the hydraulic model, discharge, flood depth, and flood volume are simulated. In terms of volumes, only $12 \mathrm{~mm}$ or $10 \%$ of the total rainfall volume reaches the outlet at Nuweiba
(Fig. 13). $40.3 \mathrm{~mm}$ (or $32.8 \%$ ) is lost to infiltration whereas $70.3 \mathrm{~mm}$ (or $57.2 \%$ ) are transmission losses. In total, $90 \%$ of the flood volume is hence lost to infiltration and transmission. Others found similar values. According to Gheith and Sultan (2002), only 3-7\% of the precipitation reached the watershed outlets for the Red Sea mountains (Eastern desert) in Egypt. El Bastawesi et al. (2009) found for Wadi Hudain (Easter Desert) in Egypt that most of the runoff infiltrates into the alluvium during its transmission through the channel.

The rainfall-runoff model is now calibrated for the extreme 2010 flash flood, but the calibrated parameter values for infiltration and transmission appeared not be transferable to simulate the other flash floods. For these (less extreme) observed flash floods, some runoff is computed, but the flood wave does not reach the outlet after routing through the wadi. This indicates that infiltration and/or transmission losses have been overestimated for these events. 


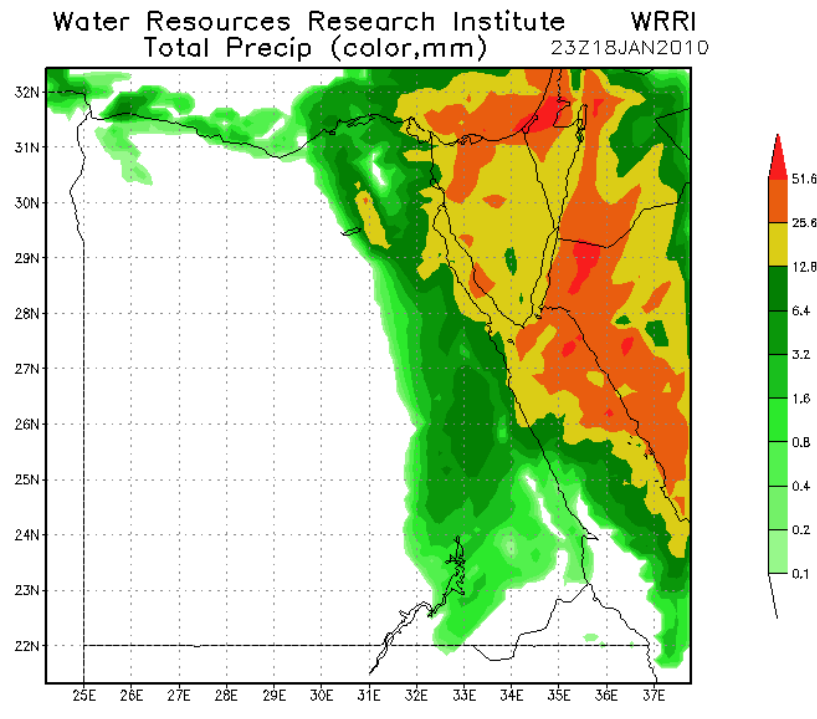

Fig. 8. Rainfall forecast by WRF for the January 2010 flash flood. The cumulative rainfall at the end of the rain event $(23 \mathrm{~h}$ on $18 \mathrm{Jan}-$ uary 2010) is shown.

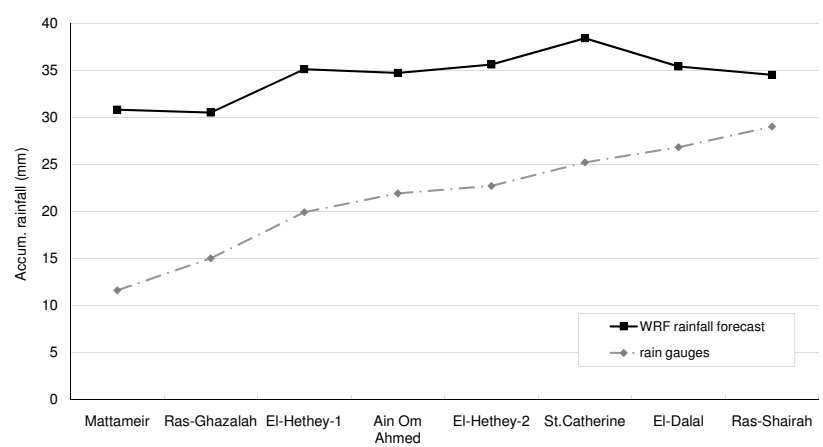

Fig. 9. Forecasted and measured rainfall in 8 stations for the January 2010 event (ranked by measured rainfall).

\section{Conclusions}

An early warning system (EWS) for flash floods has been developed for part of the Sinai peninsula of Egypt, an hyperarid area confronted with limited availability of field data, limited understanding of the response of the wadi to rainfall, and a lack of correspondence between rainfall data and observed flash flood events. This paper shows that an EWS is not a "mission impossible" when confronted with large technical and scientific uncertainties and limited data availability. The EWS is operational and issues warnings upon which can be acted by the Egyptian authorities based on rainfall forecasting and rainfall-runoff modelling. The EWS was able to forecast the last two flash floods, on 24 October 2008 and 17-18 January 2010 with an underestimation for the 2008 event and an overestimation for the 2010 event.

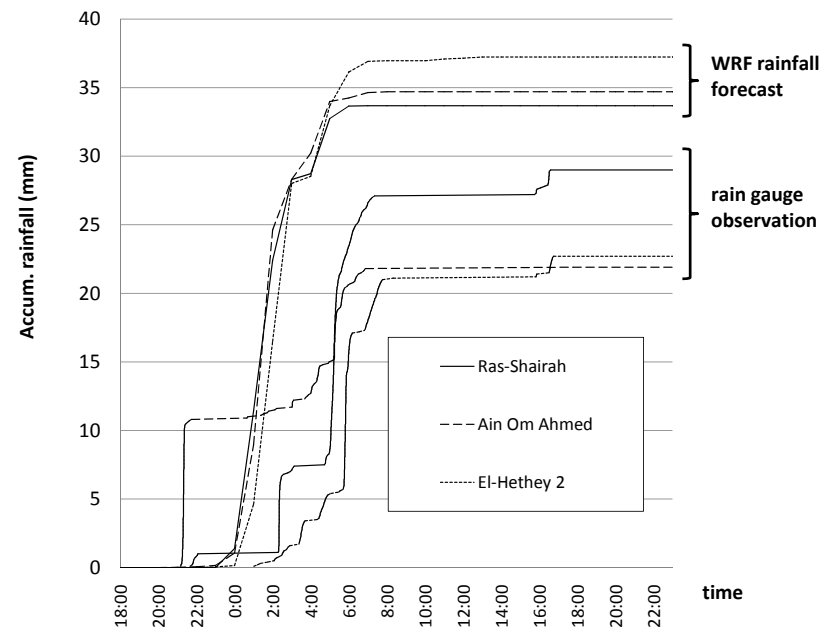

Fig. 10. Forecasted and measured rainfall in 3 stations for the January 2010 event.

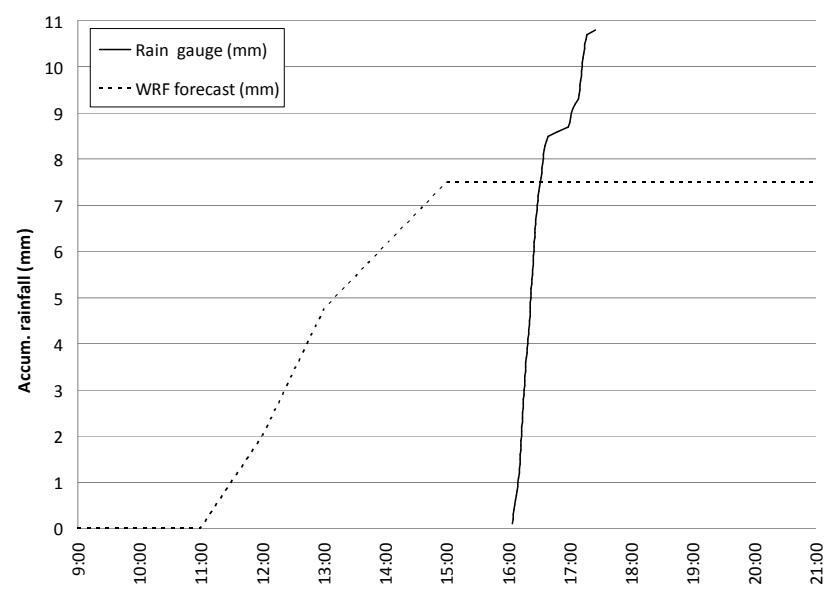

Fig. 11. Forecasted and measured rainfall for the October 2008 event (Sorah gauge).

In order to be effective in a data-poor context, the EWS has been developed and tested based on the best available information, quantitative data (field measurements, simulations and remote sensing images) complemented with qualitative "expert opinion" and local stakeholders' knowledge. Some iterations of improvements are expected in order to increase the validity of the generated warnings and the conditions under which false warnings and lack of warning (missed events) are issued.

A set of essential parameters has been identified to be estimated or measured under data-poor conditions. These are: (1) an inventory of past significant rainfall and flash flood events, (2) the spatial and temporal distribution of the rainfall events and (3) transmission and infiltration losses and (4) thresholds for issuing warnings. Over a period of 30 yr (1979-2010), only 20 significant rain events have been 


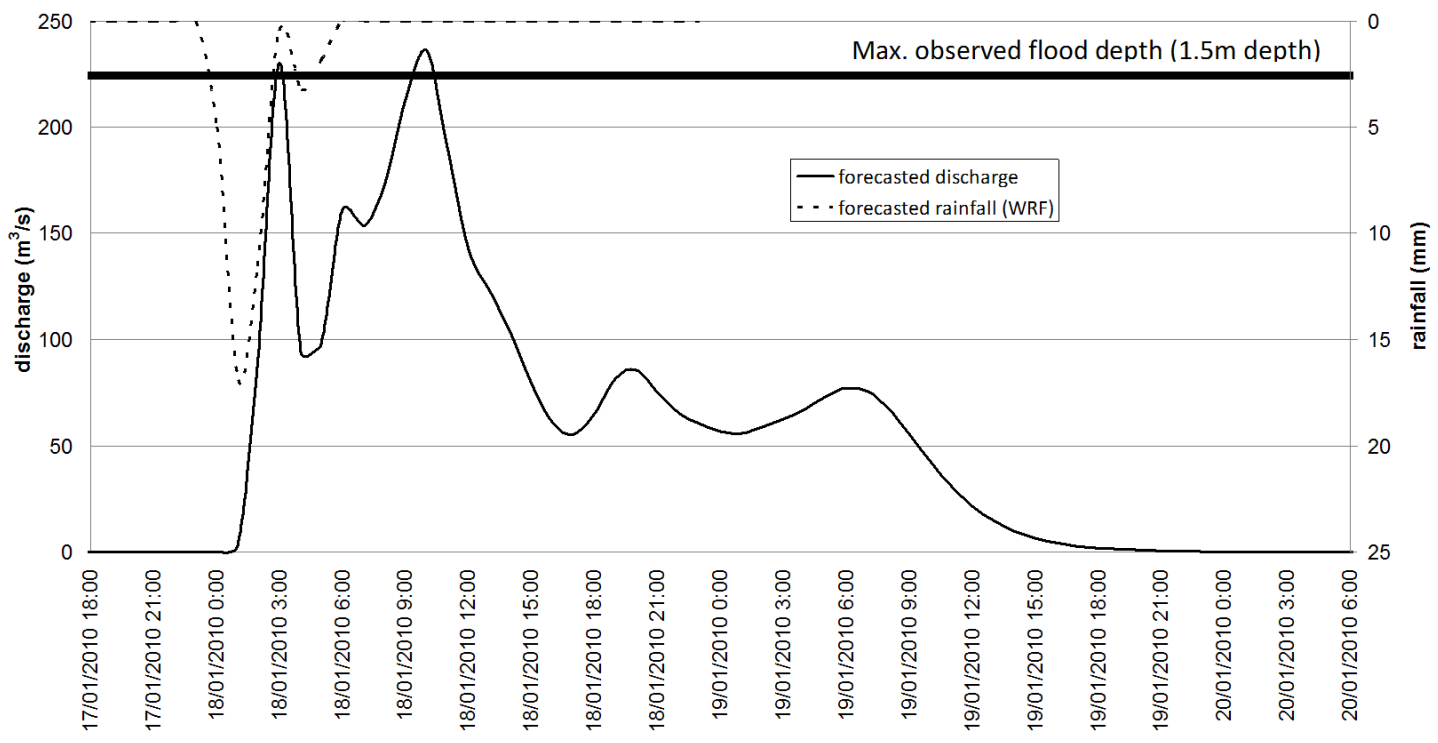

Fig. 12. Forecasted discharge at the outlet based on forecasted rainfall; the peak discharge corresponds to an observed flood depth of $1.5 \mathrm{~m}$ at the outlet of Wadi Watir.

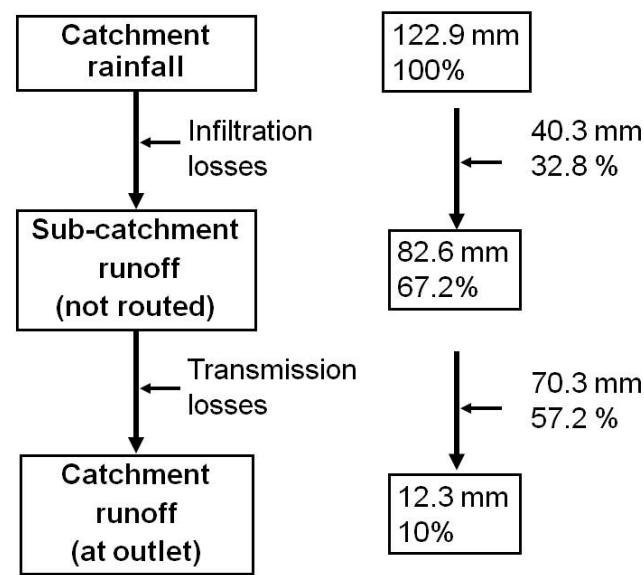

Fig. 13. Modelled infiltration and transmission losses for the 2010 flash flood.

measured. Nine of these resulted in flash floods. The relationship between rainfall volumes and the occurrence of a flash flood in hyper-arid areas is not straightforward. Although the origin of flash floods is complex and requires more research, the arguments of small scale storms (which are missed by the rain gauges) and high infiltration and transmission losses (which let a floodwave disappear before it reaches the outlet) can only partly explain the inconsistencies between the rainfall and flash flood observations. This paper demonstrates that for Wadi Watir, $50 \%$ of the storm events were regional and the other half local. Five flash floods were caused by regional storms and four by local convective storms.
WRF is proven to be an appropriate tool for rainfall forecasting in hyper-arid areas. Both local, convective events and regional (mostly non-convective) rain events are forecasted. In the lower-resolution forecasts $(30 \times 30 \mathrm{~km})$, the orographic effects could not be well represented and are underestimated. The latter is mainly important for the local, convective rain events. Satellite precipitation estimates (TRMM) proved useful to gain insights in the spatial scale and precise date of the storm events, but it captured only the regional events and missed the local events.

The results for the 2010 flash flood show that $90 \%$ of the total rainfall volume is lost to infiltration and transmission losses. For other (less extreme) observed flash floods, some runoff is computed, but the flood wave does not reach the outlet after routing through the wadi. This indicates that infiltration and/or transmission losses have been overestimated for these events. More research and field testing is hence needed before the floodwave components can be used for issuing flash flood warnings for all type of flash floods.

For an operational EWS, further evidence needs to be collected on the validity of thresholds for issuing warnings. Based on local experience with flash floods in the Sinai Peninsula, empirical thresholds are set for rainfall. In any case, given that flash floods are extreme events, statistically sound evidence will be difficult to obtain. Although the current thresholds seem to have worked, it is expected that a constant value will not be valid for the whole wadi. Small rainfall of 5-10 mm on hill slopes of exposed rock can generate minor flash floods. On the other hand, rainfall on highly transmissive alluvial wadis deposits can result in the absence of a flash flood despite significant rainfall. Evidence exists of a rain event of $50 \mathrm{~mm}$ without causing a flash flood. Hence, 
thresholds need to be evaluated by means of expert judgment and modelling. Actual discharge measurements however are not available and thus allow only qualitative calibration.

Finally, the effectiveness of an EWS is only partially determined by technological performance. A strong institutional capacity is equally important, especially skilled staff to operate and maintain the system and clear communication pathways and emergency procedures in case of an upcoming disaster. In the case of Wadi Watir, four people/institutes need to make a decision before e.g. the road is effectively closed down (WRRI, governor, mayor and traffic control). In any case, model results are not readily digestible and need to be translated into a form which is useable for decisionmaking. The major challenge to keep any EWS operational is expected to be resolved by the combination of a close interaction between the operators and decision-makers and an improved technical performance of the system.

Acknowledgements. This paper results from the FlaFloM project. It is financed by the European Commission, LIFE fund under project number LIFE06 TCY/ET/00232. We are grateful for the provided resources. We are also grateful for the support provided by the Egyptian Minister for Water and Irrigation, the Governor of the South Sinai Governorate and the Director of the South Sinai Crises and Flood Management Centre.

Edited by: F. Castelli

Reviewed by: two anonymous referees

\section{References}

Abdelkhalek, A.: Development of an early warning system for flash floods in wadi Watir - Sinai desert, PhD thesis at the Vrije Universiteit Brussel (VUB), Brussels, Belgium, 2011.

Al-Qurashi, A., McIntyre, N., Wheather, H., and Unkirch, C.: Application of the Kineros2 rainfall-runoff model to an arid catchment in Oman, J. Hydrol., 355, 91-105, doi:10.1016/j.jhydrol.2008.03.022, 2008.

Anquetin S., Braud, I., Vannier, O., Viallet, P., Boudevillain, B., Creutin, J-D., and Manus, C.: Sensitivity of the hydrological response to the variability of rainfall fields and soils for the Gard 2002 flash-flood event, J. Hydrol., 394, 134-147, 2010.

Bahat, Y., Grodek, T., Lekach, J., and Morin, E.: Rainfall-runoff modeling in a small hyper-arid catchment, J. Hydrol., 373, 204217, 2009.

Borga, M., Boscolo, P., Zanon, F., and Sangati, M.: Hydrometeorological analysis of the August 29, 2003 flash flood in the eastern Italian Alps, J. Hydrometeorol., 8, 1049-1067, 2007.

Borga, M., Gaume, E., Creutin, J. D., and Marchi, L.: Surveying flash flood response: gauging the ungauged extremes, Hydrol. Process., 22, 3883-3885, doi:10.1002/hyp.7111, 2008.

Chow, V., Maidment, R., and Mays, L.: Applied Hydrology, McGraw-Hill, 1988.

Collier, C. G.: Flash flood forecasting: what are the limits of predictability, Q. J. Roy Meteorol. Soc., 133, 3-23, 2007.

Cools, J., Meyus, M., Woldeamlak, S. T., Batelaan, O., and De Smedt, F.: Large-scale GIS-based hydrogeological modelling of
Flanders: a tool for groundwater management, Environ. Geol., 50, 1201-1209, 2006.

El Afandi, G.: Developing flash-flood guidance in Egypt's Sinai Peninsula with the Weather Research Forecast (WRF) model, Int. J. Meteorol., March 2010, 35, 347, 75-82, 2010.

El-Bastawesi, M., White, K., and Nasr, A.: Integration of remote sensing and GIS for modelling flash floods in Wadi Hudain catchment, Egypt. Hydrol. Process., 23, 1359-1368, 2009.

Foody, G. M., Ghoneim, E. M., and Arnell, N. W.: Predicting locations sensitive to flash flooding in an arid environment, J. Hydrol., 292, 48-58, 2004.

Gheith, H. and Sultan, M.: Construction of a hydrologic model for estimating Wadi runoff and groundwater recharge in the Eastern Desert, Egypt, J. Hydrol., 263, 36-55, 2002.

Green, W. H. and Ampt, G. H.: Studies on soil physics, part I, the flow of air and water through soils, J. Agr. Sci., 4, 1-24, 1911.

Harms, R. W. and Verworn, H. R.: Hystem, ein hydrologisches Stadtentwässerungmodell, Teil 1: Modellbeschreibung, Korrespondenz Abwasser, Heft 2, Hannover, 1984.

Huffman G. J. and Bolvin, D. T.: Real-Time TRMM Multi-Satellite Precipitation Analysis Data Set Documentation. Laboratory for Atmospheres, NASA Goddard Space Flight Center and Science Systems and Applications, Inc. Technical note, 2008.

Kahana, R., Ziv, B., Enzel, Y., and Dayan, U.: Synoptic climatology of major floods in the Negev Desert, Int. J. Climatol., 22, 7, 867$882,2002$.

Lin, X.: Flash floods in arid and semi-arid zones, UNESCO, Paris, 65 pp., 1999.

Marchi, L., Borga, M., Preciso, E., and Gaume, E.: Characterisation of selected extreme flash floods in Europe and implications for flood risk management, J. Hydrol, 394, 118-133, doi:10.1016/j.jhydrol.2010.07.017, 2010.

Michaud, J. D. and Sorooshian, S.: Comparison of simple versus complex distributed runoff models on a midsized semi-arid watershed, Water Resour. Res., 30, 593-605, 1994.

Morin, E., Goodrich, D. C., Maddox, R. A., Gao, X. G., Gupta, H. V., and Sorooshian, S.: Spatial patterns in thunderstorm rainfall events and their coupling with watershed hydrological response, Adv. Water Res., 29, 843-860, doi:10.1016/j.advwatres.2005.07.014, 2006.

Morin, E., Jacoby, Y., Navon, S., and Bet-Halachmi, E. B.: Towards flash-flood prediction in the dry Dead Sea region utilizing radar rainfall information, Adv. Water Res., 32, 1066-1076, 2009.

Norbiato, D., Borga, M., Sangati, M., and Zanon, F.: Regional frequency analysis of extreme precipitation in the eastern Italian Alps and the August 29, 2003 flash flood, J. Hydrol., 345, 149166, 2007.

Pilgrim, D. H., Chapman, T. G., and Doran, D. G.: Problems of rainfall-runoff modelling in arid and semiarid regions, Hydrol. Sci. J., 33, 379-400, 1988.

Skamarock, W. C., Klemp, J. B., Dudhia, J., Gill, D. O., Barker, D. M., Duda, M. G., Huang, X.-Y., Wang, W., and Powers, J. G.: A description of the Advanced Research WRF Version 3, NCAR Tech. Note, NCAR/TN-475+STR, 113 pp., 2008.

Tolba, A. F. and Gaafer, K.: On estimation of potential evapotranspiration in Egypt Egyptian Meteorological Authority- Meteorological Research Bulletin, ISSN 1687-1014, 2003.

Wallingford Software: InfoWorks-RS version 9.0, Wallingford, UK, 2008. 
Wheather, H. S.: Hydrological processes in arid and semi-arid areas. in: Hydrology of Wadi systems, edited by: Wheather, H. S. and Al-Weshah, R. A., UNESCO, Paris, 2002.

WRRI: South Sinai Water Resources Development Project, Report n.3: Hydrological studies at Wadi Watir and its tributaries, 1995.

WRRI: Evaluation, Development and Execution of Some Flash Flood Protection Works - Wadi Watir - South Sinai, Water Resour. Res. Institute, Cairo, 70 pp., 2004.

Yakir, H. and Morin, E.: Hydrologic response of a semi-arid watershed to spatial and temporal characteristics of convective rain cells, Hydrol. Earth Syst. Sci., 15, 393-404, doi:10.5194/hess15-393-2011, 2011.
Yatheendradas, S., Wagener, T., Gupta, H., Unkrich, C., Goodrich, D., Schaffner, M., and Stewart, A.: Understanding uncertainty in distributed flash flood forecasting for semiarid regions, Water Resour. Res., 44, W05S19, doi:10.1029/2007WR005940, 2008.

USDA: Urban hydrology for small watersheds, Technical Release 55 (TR-55) Natural Resources Conservation Service, Conservation Engineering Division, United States Department of Agriculture, 2nd Edn., 1986. 